\title{
Mechanism research on technical policy of liquid extraction depressurization development for buried hill reservoirs
}

\author{
Huajiao Guan ${ }^{1}$, Xiaoying $\mathrm{Shi}^{1 *}$, Yayuan $\mathrm{Tao}^{1}, \mathrm{Xianqiu} \mathrm{Chao}^{1}$ and Yumiao $\operatorname{Tan}^{1}$ \\ ${ }^{1}$ Exploration and Development Research institute of HuaBei Oilfield Company, Renqiu 062552, China
}

\begin{abstract}
Most of buried hill reservoirs are in the late stage of water flooding development, especially for this kind of reservoir with large water-oil volume ratio, it is more difficult to develop the residual oil in matrix system. This article presents a new idea about technical policy of extraction depressurization development which has not been studied in domestic and abroad, and analyses the major influence factor of liquid extraction depressurization by dual-media numerical simulation in depth. The results show that it can increase the oil production in matrix system to a greater extent by liquid extraction depressurization. The liquid extraction capacity is the most important factor which contains the effect of uniform speed liquid extraction, variable speed liquid extraction and periodic liquid extraction. Under the condition of keeping stable production, the larger the liquid volume extracted, the faster pressure dropped, and the more oil will be discharged in matrix system. According to these results, this paper suggests the reasonable technical policy of liquid extraction depressurization, and it is of great significance to obtain good effect of slowing down water cut and enhancing oil recovery in depressurization development of the buried hill reservoirs with high water cut and enough energy.
\end{abstract}

\section{Introduction}

Most of buried hill reservoirs have entered the late stage of water flooding development with high water cut. At present, the production of reservoirs has decreased rapidly, the residual oil was mainly in matrix systems. It is difficult to develop in conventional method. Depressurization development is a special way to improve oil recovery by unstable water injection which makes the medium with different permeability performance redistribute pressure at different speeds, by changing the water injection amount or liquid production volume to play the role of inside or external natural energy (including driving pressure, elastic force, gravity and capillary force) in reservoir for achieving enhanced oil recovery [1].Thus, it is necessary to carry out the research about technical policy of depressurization development.

According to this view, a number of related experiments about depressurization development were carried out, especially its application to Renqiu buried hill reservoir in Huabei oilfield, and these researches all adopted depressurization method by controlling or stopping water injection [2-10]. However, their effects were not obvious on buried hill reservoirs with large water-oil volume ratio, for example Liubei oilfield. It is because the lager water-oil-volume ratio is, the more difficult the pressure drops, furthermore, the reasonable depressurization methods are different with various natural energies in the reservoir.

Recent years, available studies mainly focus on the mechanism of oil displacement in matrix of fractured buried hill reservoir [11-15]. But, there are no studies about technical policy of the depressurization development in reservoirs with large water-oil-volume ratio so far. This article introduces the liquid extraction depressurization method, and takes the $\mathrm{Y}$ buried hill reservoir which water-oil volume ratio close to 200 times as a representative, aiming at finding out oil-increasing mechanism of rock block system and the major influence factor in liquid extraction depressurization development, and predicting the effect of liquid extraction depressurization development scheme through dual-media numerical simulation. Then, the reasonable technical policy of liquid extraction depressurization has been designed for achieving the maximum benefit in slowing down water cut and enhancing oil recovery in this type of reservoir.

\section{Model establishment and history matching}

Taking the Y buried hill reservoir as a representative, it is a typically low porosity and high permeability dolomite fracture reservoir. A single porosity and double permeability model is established, the total number of grids is $88 \times 117 \times 188=1935648$, and the compositional model has been used in Eclipse. In order to quantitatively evaluate the effect of liquid extraction depressurization development, the reservoir is carried out history matching by numerical simulation. The comparison between history

"Corresponding author's e-mail: yjy_sxy@petrochina.com.cn 
matching and actual production is shown in Table 1 .

Table 1. Comparison between history matching and actual production

\begin{tabular}{cccccc}
\hline Parameters & $\begin{array}{c}\text { Geological } \\
\text { reserves } \\
\left(10^{4} \mathrm{t}\right)\end{array}$ & $\begin{array}{c}\text { Cumulative oil } \\
\text { production } \\
\left(10^{4} \mathrm{t}\right)\end{array}$ & $\begin{array}{c}\text { Cumulative liquid } \\
\text { production } \\
\left(10^{4} \mathrm{t}\right)\end{array}$ & $\begin{array}{c}\text { Total } \\
\text { pressure drop } \\
(\mathrm{MPa})\end{array}$ & $\begin{array}{c}\text { Composite } \\
\text { water cut }(\%)\end{array}$ \\
\hline Actual production & 1695.92 & 530.29 & 3966.14 & 1.83 & 97.35 \\
History matching & 1716.9 & 536.16 & 3936.12 & 1.69 & 98.19 \\
\hline
\end{tabular}

\section{Analysis of oil-increasing mechanism}

By depressurizing, it can change the driving mode of reservoir, and make the elastic force and imbibition of block play a better role, also decrease seepage capacity of the large fracture and reduce its interference to the middle or small crack holes and the block system. Depressurization development motivates the production potential of medium or small fractured holes and block system, aiming to slow down the increasing of water, enhance oil recovery and improve the development effect in the middle and late stages [16-18].

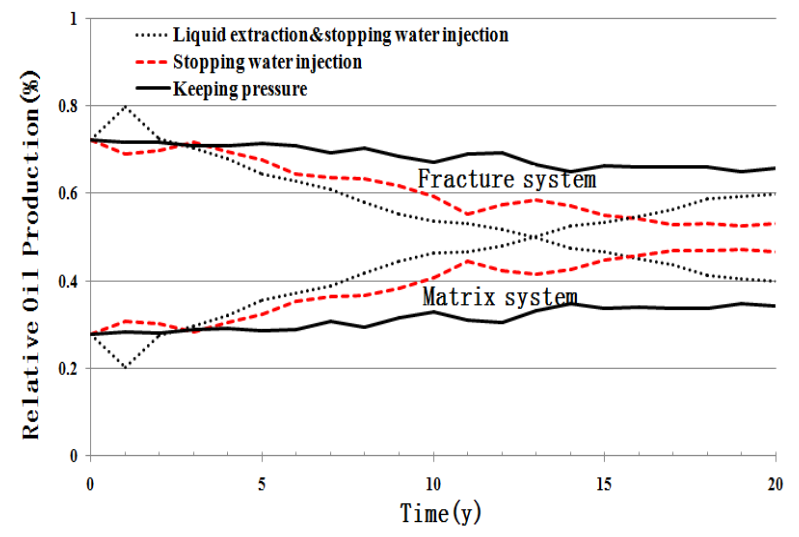

Figure 1. Comparison of relative oil production between fracture system and matrix system in different development modes.

The results of numerical simulation in Figure 1 are as follows: (1) the oil production contribution of the fracture system during the depressurization development is lower than that of keeping up pressure, while the oil contribution of matrix system is higher. (2) In the depressurization, stopping water injection compared with the liquid extraction as well as stopping water injection, due to the liquid volume suddenly increases at the initial stage of liquid extraction, the rising water cut will cause the relative oil production of the fracture system to be higher than the matrix system in a short term. In fact, the pressure drop extent of the liquid extraction is larger, and the oil production of the rock block system will be higher. (3) With different pressure drop levels in depressurization development, the oil production contribution of the matrix system increases from $23 \%$ to $60 \%$. It indicates that the role of the matrix system in oil production has enhanced in the depressurization of the reservoir. The greater the pressure drops, the stronger the oil production ability of the rock block is. Especially for the reservoirs with high water cut in the late stage of development, the reservoir can effectively slow down the water cut and increase the discharge of oil by liquid extraction depressurizing, in addition, the oil recovery has been improved.

\section{Results and discussion}

The water-oil volume ratio of $\mathrm{Y}$ buried hill reservoir is 191.8 times. The water body is large and the natural energy is sufficient. Since it is commissioned in 1977, the oil recovery has been $30.7 \%$ and the comprehensive water cut has been $97.2 \%$ until now. The reservoir is in the late stage of development with high water cut at present. During the production process, the reservoir adopts these two methods of extracting liquid and stopping injection for depressurization development. The implementation time of depressurization is short, and the effect obtained is not significant enough. Up to now, the reservoir pressure has only decreased by $1.83 \mathrm{MPa}$. In order to further deepen the research on depressurization development technical policies of this kind of reservoir, the depressurization method should be set to extract the liquid and simultaneously stop the water well injection, and analysing the influencing factors of the liquid extraction depressurization from the following points.

\subsection{Effect on the structural position of liquid extraction well}

The buried hill reservoir can be obviously divided into high, waist and low parts in the structure. In this research, a total of 9 liquid extraction wells were selected. In general, choosing the well with low oil production or being shut state as the liquid extraction well. Under the condition of the same total liquid volume, comparing the following two cases, case 1 is that liquid extraction wells daily extracting liquid $4500 \mathrm{~m}^{3}$ only in low part of the structure; case 2 is that liquid extraction wells daily extracting liquid $4500 \mathrm{~m}^{3}$ both in waist and low part of the structure. The numerical simulation is used to predict the production dynamics in 20 years after 2018 . 
Table 2. Comparison of production quota of extraction liquid well in different structure in the 20th year

\begin{tabular}{ccccccccc}
\hline Case name & $\begin{array}{c}\text { Daily liquid } \\
\left(\mathrm{m}^{3}\right)\end{array}$ & $\begin{array}{c}\text { Daily oil } \\
(\mathrm{t})\end{array}$ & $\begin{array}{c}\text { Composite } \\
\text { water } \\
\text { cut } \\
(\%)\end{array}$ & $\begin{array}{c}\text { Formation } \\
\text { pressure } \\
(\mathrm{MPa})\end{array}$ & $\begin{array}{c}\text { Total } \\
\text { pressure } \\
\text { drop } \\
(\mathrm{MPa})\end{array}$ & $\begin{array}{c}\text { Degree of } \\
\text { reserve } \\
\text { recovery } \\
(\%)\end{array}$ & $\begin{array}{c}\text { Cumulative } \\
\text { increment } \\
\text { oil } \\
\left(10^{4} \mathrm{t}\right)\end{array}$ & $\begin{array}{c}\text { Matrix } \\
\text { increment } \\
\text { oil } \\
\left(10^{4} \mathrm{t}\right)\end{array}$ \\
\hline Case1 & 7289 & 23.51 & 99.68 & 24.18 & 4.65 & 33.25 & 27.46 & 10.86 \\
Case2 & 7287 & 22.84 & 99.68 & 24.18 & 4.65 & 33.26 & 27.67 & 10.31 \\
\hline
\end{tabular}

Table 2 shows when the total volume of liquid is the same, the pressure drop rate and water cut of case 2 is the same as case 1, but the cumulative oil production and degree of reserve recovery are higher. Figure 2 and Figure 3 show the water cut of case 2 rising relatively slowly, but the annual oil discharge of the matrix is lower, which

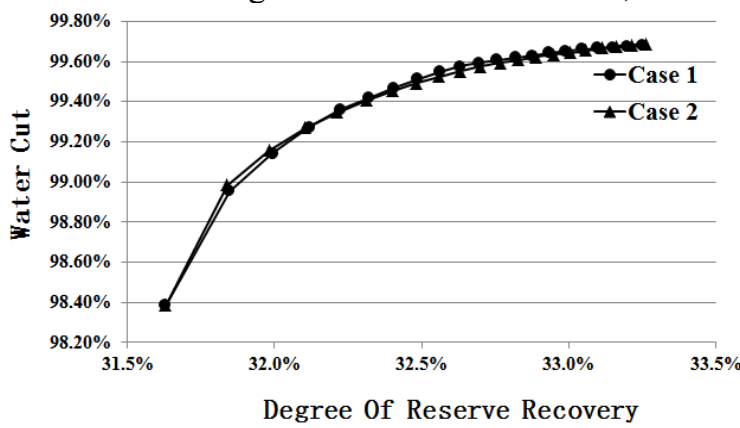

Figure 2. Comparison of water cut.

\subsection{Effect of liquid extracting capacity}

In the study of the liquid extracting capacity, the selected liquid extraction wells and the structural position are all in the same, only changing the liquid extracting capacity. Mainly analysing the effect of uniform speed liquid extraction, variable speed liquid extraction, and sequence of variable speed liquid extraction, moreover, the maximum daily liquid volume for ensuring stable production of the reservoir will be defined for the Y buried hill reservoir. indicates that the higher cumulative oil production of case 2 is mainly caused by the higher oil discharge of fracture system. Overall, the effect of extraction depressurization development of these two cases is similar, but it is more practical and convenient in the development according to case 1 .

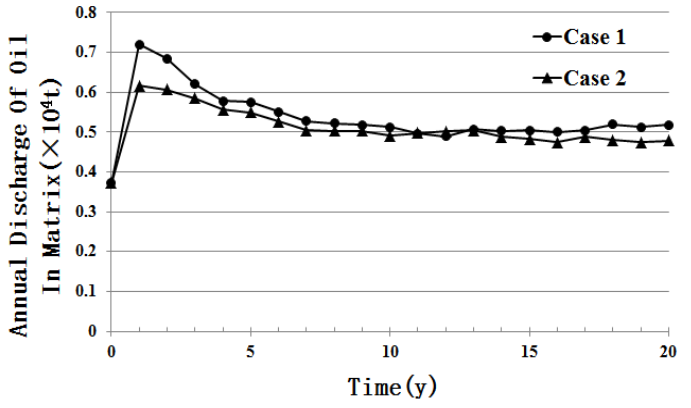

Figure 3. Comparison of annual oil discharge in matrix system.

\subsubsection{Effect of uniform speed liquid extraction}

In this paper, the uniform speed liquid extraction is always carried out with the same daily liquid production during the 20-year prediction period. A total of 4 sets of uniform speed liquid extraction cases are calculated by numerical simulation. These four cases are as follows: daily liquid volume of case 3 is $2700 \mathrm{~m}^{3}$, case 4 is $4500 \mathrm{~m}^{3}$, case 5 is $6300 \mathrm{~m}^{3}$, case 6 is $8100 \mathrm{~m}^{3}$. Table 3 shows the larger the capacity of liquid extraction is, the faster the pressure drops, the higher the cumulative oil production and the amount of oil discharges from the matrix, the faster the water cut rises.

Table 3. Comparison of different liquid extracting capacity in uniform liquid extraction in the 20th year

\begin{tabular}{ccccccccc}
\hline Case name & $\begin{array}{c}\text { Daily liquid } \\
\left(\mathrm{m}^{3}\right)\end{array}$ & $\begin{array}{c}\text { Daily oil } \\
(\mathrm{t})\end{array}$ & $\begin{array}{c}\text { Composite } \\
\text { water } \\
\text { cut } \\
(\%)\end{array}$ & $\begin{array}{c}\text { Formation } \\
\text { pressure } \\
(\mathrm{MPa})\end{array}$ & $\begin{array}{c}\text { Total } \\
\text { pressure } \\
\text { drop } \\
(\mathrm{MPa})\end{array}$ & $\begin{array}{c}\text { Degree of } \\
\text { reserve } \\
\text { recovery } \\
(\%)\end{array}$ & $\begin{array}{c}\text { Cumulative } \\
\text { increment } \\
\text { oil } \\
\left(10^{4} \mathrm{t}\right)\end{array}$ & $\begin{array}{c}\text { Matrix } \\
\text { Increment } \\
\text { oil } \\
\left(10^{4} \mathrm{t}\right)\end{array}$ \\
\hline Case 3 & 5489.00 & 19.68 & 99.64 & 25.34 & 3.49 & 33.07 & 24.45 & 9.11 \\
Case 4 & 7289.00 & 23.51 & 99.68 & 24.18 & 4.65 & 33.25 & 27.46 & 10.86 \\
Case 5 & 8550.27 & 26.43 & 99.69 & 23.05 & 5.78 & 33.41 & 30.23 & 12.55 \\
Case 6 & 8238.55 & 27.53 & 99.67 & 22.16 & 6.67 & 33.55 & 32.49 & 14.00 \\
\hline
\end{tabular}




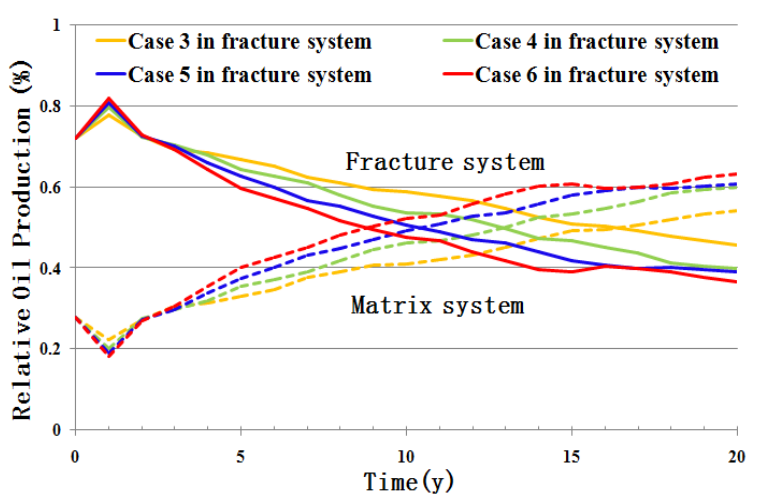

Figure 4. Comparison of relative oil production.

Figure 4 shows the larger the liquid volume is, the earlier the matrix system plays a major oil production, and Figure 5 shows if the capacity of liquid extraction is too large, it will result in the unstable development of reservoir. For the liquid extraction depressurization, even though the larger the volume of liquid extraction can make the higher the oil production, not the larger the better. It just would be that only under the condition of ensuring stable production of the reservoir.

\subsubsection{Effect of variable speed liquid extraction}

In this paper, the variable speed liquid extraction is that the reservoir is developed with a certain daily liquid production in the first 10 years and another daily liquid production volume in the next 10 years during a 20 -year forecast period. The difference between the uniform speed and the variable speed liquid extraction, and the change order of the daily liquid volume in the variable speed liquid extraction are analysed and compared under the same total liquid volume.

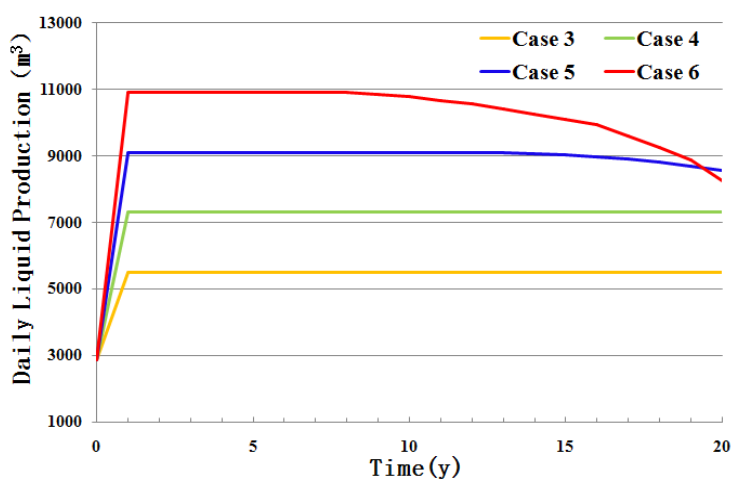

Figure 5. Comparison of daily liquid production.

\subsubsection{Comparison between uniform speed and variable speed liquid extraction}

In the 20-year prediction period, when the total volume of liquid extraction is the same, these two sets of schemes are analysed: one is case 4, another is case 7 that in variable speed liquid extraction the liquid volume extract in the first 10 years is $6300 \mathrm{~m}^{3}$, and the next 10 years is changed to $2700 \mathrm{~m}^{3}$. The results shown in Figure 6 (a) and Table 4 indicate that under the same conditions of total liquid extraction, the total pressure drop of the uniform speed liquid extraction and the variable speed liquid extraction are the same, but the recovery degree, cumulative oil production and matrix oil discharge of the variable speed liquid extraction are slightly higher than that of the uniform.

Figure 6(b) shows that the oil discharge of the matrix system begins to decrease in the current year actually, but the relative production of the matrix system has an instantaneous increase when the daily liquid extraction amount is reduced to $2700 \mathrm{~m}^{3}$ in the variable speed liquid extraction. It is mainly due to the different permeability of the fracture system and the matrix system as well as the different reaction rate to the production and pressure, thus, the decline rate of production in the fracture system is faster than that in matrix system when the amount of liquid is reduced.

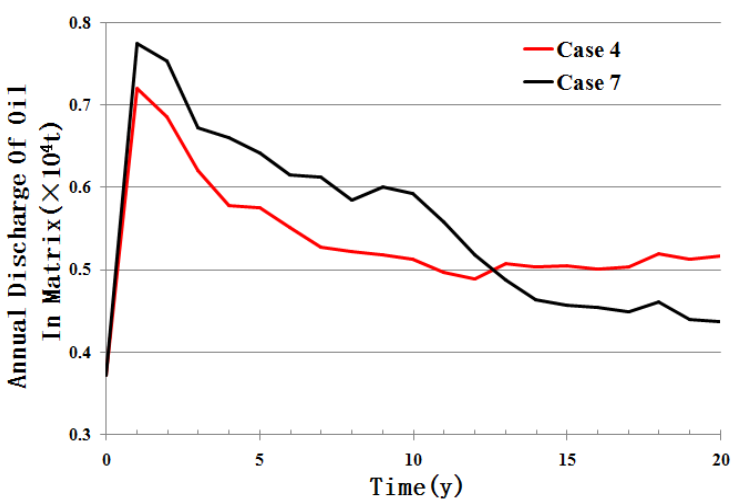

(a)

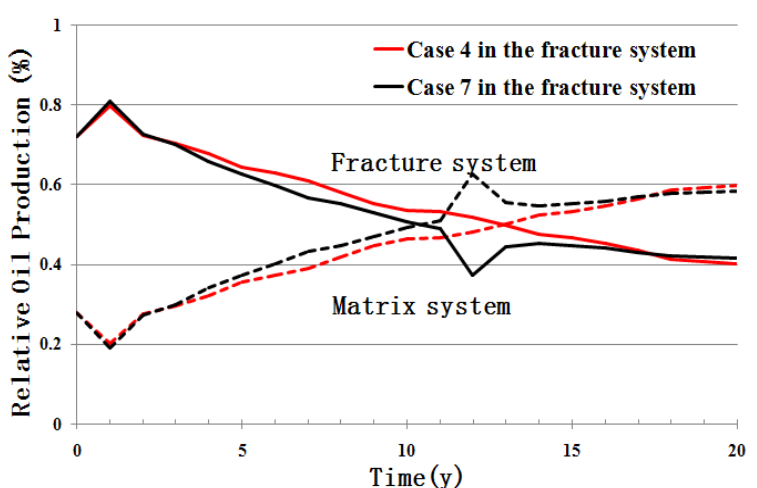

(b)

Figure 6. Comparison of production quota in different liquid extraction modes. 
Table 4. Comparison between uniform speed and variable speed liquid extraction in the 20th year

\begin{tabular}{ccccccccc}
\hline Case name & $\begin{array}{c}\text { Daily liquid } \\
\left(\mathrm{m}^{3}\right)\end{array}$ & $\begin{array}{c}\text { Daily oil } \\
(\mathrm{t})\end{array}$ & $\begin{array}{c}\text { Composite } \\
\text { water } \\
\text { cut } \\
(\%)\end{array}$ & $\begin{array}{c}\text { Formation } \\
\text { pressure } \\
(\mathrm{MPa})\end{array}$ & $\begin{array}{c}\text { Total } \\
\text { pressure } \\
\text { drop } \\
(\mathrm{MPa})\end{array}$ & $\begin{array}{c}\text { Degree of } \\
\text { reserve } \\
\text { recovery } \\
(\%)\end{array}$ & $\begin{array}{c}\text { Cumulative } \\
\text { increment } \\
\text { oil } \\
\left(10^{4} \mathrm{t}\right)\end{array}$ & $\begin{array}{c}\text { Matrix } \\
\text { increment } \\
\text { oil } \\
\left(10^{4} \mathrm{t}\right)\end{array}$ \\
\hline Case 4 & 7289.00 & 23.51 & 99.68 & 24.18 & 4.65 & 33.25 & 27.46 & 10.86 \\
Case 7 & 5489.00 & 20.22 & 99.63 & 24.19 & 4.65 & 33.27 & 27.87 & 11.23 \\
\hline
\end{tabular}

\subsubsection{Effect of shift sequence in the daily extracting liquid volume}

Under the same condition of total liquid volume, only the first 10 years and the last 10 years of the daily liquid volume in the 20-year prediction period are exchanged. Calculating two sets of schemes, case 8 is that in the first 10 years daily volume of liquid extraction is $4500 \mathrm{~m}^{3}$, then changed $6300 \mathrm{~m}^{3}$ in the next 10 years, case 9 is that in the first 10 years daily volume of liquid extraction is $6300 \mathrm{~m}^{3}$, then changed $4500 \mathrm{~m}^{3}$ in the next 10 years. Table 5 shows that although the degree of pressure drop and the total amount of liquid extraction is the same, the pressure drop is much faster when the volume of liquid extraction is larger in the early stage. When the reservoir pressure is reduced to a certain extent, continue changing to a large amount of liquid extraction will result in the reservoir not being able to stabilize the liquid production. As the results, the degree of reserve recovery, cumulative oil production and increment oil of matrix must be higher with method of large volume at the beginning, following by the small volume in the variable speed liquid extraction for depressurization development.

Table 5. Comparison of different sequence of daily extracting liquid in variable speed in the 20th year

\begin{tabular}{ccccccccc}
\hline Case name & $\begin{array}{c}\text { Daily liquid } \\
\left(\mathrm{m}^{3}\right)\end{array}$ & $\begin{array}{c}\text { Daily oil } \\
(\mathrm{t})\end{array}$ & $\begin{array}{c}\text { Composite } \\
\text { water } \\
\text { cut } \\
(\%)\end{array}$ & $\begin{array}{c}\text { Formation } \\
\text { pressure } \\
(\mathrm{MPa})\end{array}$ & $\begin{array}{c}\text { Total } \\
\text { pressure } \\
\text { drop } \\
(\mathrm{MPa})\end{array}$ & $\begin{array}{c}\text { Degree of } \\
\text { reserve } \\
\text { recovery } \\
(\%)\end{array}$ & $\begin{array}{c}\text { Cumulative } \\
\text { increment } \\
\text { oil } \\
\left(10^{4} \mathrm{t}\right)\end{array}$ & $\begin{array}{c}\text { Matrix } \\
\text { increment } \\
\text { oil }\end{array}$ \\
$\begin{array}{cccccccc}\left(10^{4} \mathrm{t}\right) \\
\text { Case } 8\end{array}$ & 8793.67 & 26.68 & 99.70 & 23.61 & 5.22 & 33.32 & 28.71 & 11.55 \\
Case 9 & 7255.97 & 23.93 & 99.67 & 23.54 & 5.29 & 33.35 & 29.22 & 12.00 \\
\hline
\end{tabular}

\subsubsection{Definition of maximum daily liquid volume}

In the depressurization of liquid extraction, no matter what kind of liquid extraction method is used for depressurization, the amount of liquid extraction is the most important factor affecting the depressurization of liquid extraction. According to the analysis of the mechanism of depressurization, the larger the amount of liquid extraction is, the faster the pressure of reservoir drop, so that the rock block system can exert the elastic force and imbibition effect better to increase the oil discharge of the matrix. However, larger amount of liquid extraction is not better. Taking Y buried hill reservoir as example, in order to ensure the stable liquid production of the reservoir, numerical simulation is used to compare the daily liquid production of the reservoir in different volume of daily average liquid extraction during the 20-year prediction period. These cases are case 4 , case 5 , case 6 , case 7 , case 8 , case 9 , case 10 which is in the first 10 years daily volume of liquid extraction is $6300 \mathrm{~m}^{3}$ then changed $4500 \mathrm{~m}^{3}$ in the next 10 years, and case 11 that is in the first 10 years daily volume of liquid extraction is $6300 \mathrm{~m}^{3}$ then changed $4500 \mathrm{~m}^{3}$ in the next 10 years.

Table 6. Changes of daily liquid production of reservoir in different liquid extraction volume in 20 years

\begin{tabular}{ccc}
\hline Case name & Daily average liquid extraction $\left(\mathrm{m}^{3}\right)$ & Daily fluid stability of reservoir \\
\hline Case 3 & 2700 & Stable production \\
Case 4 & 4500 & Stable production \\
Case 5 & 6300 & Unstable production from the 12th year \\
Case 6 & 8100 & Unstable production from the 9th year \\
Case 9 & 5400 & Unstable production from the 19th year \\
Case 7 & 4500 & Stable production \\
Case 10 & 5400 & Unstable production from the 9th year \\
Case 11 & 6300 & Unstable production from the 9th year \\
\hline
\end{tabular}

The result shown in Table6 suggests that, within 20 years, the total daily average liquid volume of the Y buried hill reservoir is more than $5400 \mathrm{~m}^{3}$ will result in unstable production, while the daily average liquid volume is equal to $5400 \mathrm{~m}^{3}$, the daily liquid production volume of the reservoir has a downward trend at the end of 20 years. The maximum daily average liquid volume of the $\mathrm{Y}$ buried hill reservoir is defined as $5400 \mathrm{~m}^{3}$, in the meantime the 
extraction time of the large liquid volume in the early stage should not be too long.

\subsubsection{Effect of cyclic liquid extraction}

Combined with economic, environmental protection and other factors, the research of cyclic liquid extraction is carried out $[19,20]$. Comparing case 12 and case 13 these two cases under the same liquid extraction amount, case 12 is to recover the original liquid volume and stop water injection after liquid extraction, case 13 is to recover the water flooding after liquid extraction, both are in 20 years,

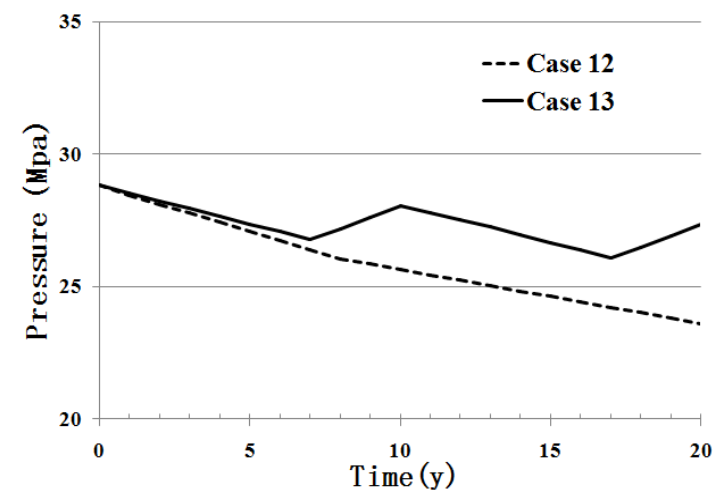

Figure 7. Comparison of pressure. it is a cycle per 10 years. Figure 7 shows the total pressure drop of case 13 is smaller than case12, which is because the pressure of fracture system is recovered faster after the water injection, although the pressure of recovering liquid is the same as that of recovering water injection in the previous period; Figure 8 shows the cumulative oil production of recovering fluid volume is the same as that of recovery water injection in the first cycle, however, the water channel along the crack will cause the water cut to rise after recovering the water injection, while the matrix has not been able to be infiltrated in time and will be flooded which results in the production drawdown after recovering water injection in the second cycle.

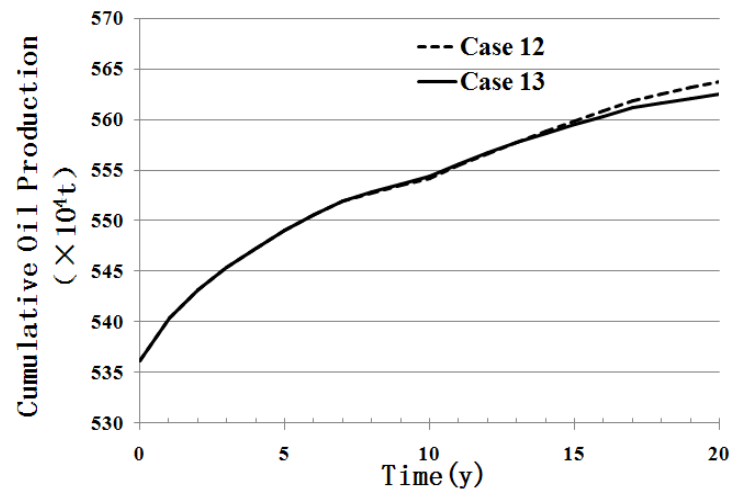

Figure 8. Comparison of cumulative oil production.

Table 7. Comparison of production quota of different extraction mode in the same volume in 20 years

\begin{tabular}{ccccccccc}
\hline Case name & $\begin{array}{c}\text { Daily liquid } \\
\left(\mathrm{m}^{3}\right)\end{array}$ & $\begin{array}{c}\text { Daily oil } \\
(\mathrm{t})\end{array}$ & $\begin{array}{c}\text { Composite } \\
\text { water } \\
\text { cut } \\
(\%)\end{array}$ & $\begin{array}{c}\text { Formation } \\
\text { pressure } \\
(\mathrm{MPa})\end{array}$ & $\begin{array}{c}\text { Total } \\
\text { pressure } \\
\text { drop } \\
(\mathrm{MPa})\end{array}$ & $\begin{array}{c}\text { Degree of } \\
\text { reserve } \\
\text { recovery } \\
(\%)\end{array}$ & $\begin{array}{c}\text { Cumulative } \\
\text { increment } \\
\text { oil } \\
\left(10^{4} \mathrm{t}\right)\end{array}$ & $\begin{array}{c}\text { Matrix } \\
\text { Increment } \\
\text { oil } \\
\left(10^{4} \mathrm{t}\right)\end{array}$ \\
\hline Case 4 & 7289.00 & 23.51 & 99.68 & 24.18 & 4.65 & 33.25 & 27.46 & 10.86 \\
Case 7 & 5489.00 & 20.22 & 99.63 & 24.19 & 4.65 & 33.27 & 27.87 & 11.23 \\
Case 12 & 2789.00 & 16.06 & 99.42 & 24.26 & 4.57 & 33.26 & 27.62 & 11.17 \\
Case 13 & 2789.00 & 11.37 & 99.59 & 27.34 & 1.49 & 33.19 & 26.38 & 8.97 \\
\hline
\end{tabular}

In addition, a comparison is made between the uniform speed and the variable speed liquid extraction method under the same liquid extraction amount. Table 7 shows that: under the same amount of liquid extraction, the oil production of the variable speed liquid is the highest. Even though the oil production of cyclic liquid extraction is also high, in the stage its pressure drop is small, the degree of matrix increment is low as well. So, for buried hill reservoirs with large water-oil volume ratio and high water cut, like Y, they are not recommended to use the cyclic liquid extraction method.

\subsection{Program optimization}

In the study of the liquid extracting capacity, the selected liquid extraction wells and the structural position are all in the same, only changing the liquid extracting capacity. Mainly analysing the effect of uniform speed liquid extraction, variable speed liquid extraction, and sequence of variable speed liquid extraction, moreover, the maximum daily liquid volume for ensuring stable production of the reservoir will be defined for the $\mathrm{Y}$ buried hill reservoir.

In view of the research on the technical policy mechanism of the liquid extraction depressurization, designing three sets of schemes for $\mathrm{Y}$ buried hill reservoir according to the sequence that the large volume first, and the small volume next in variable speed liquid extraction method, also under the condition of the total daily average liquid extraction volume is not more than $5400 \mathrm{~m}^{3}$ within 20-year prediction period, choosing 9 liquid extraction wells. These three cases are case 9 , case 14 , and case 15 . Case 14 is extracting liquid $8100 \mathrm{~m}^{3}$ for 8 years, and then extracting $3600 \mathrm{~m}^{3}$ for 12 years, case 15 is extracting liquid $10800 \mathrm{~m}^{3}$ for 6 years, and then extracting $3000 \mathrm{~m}^{3}$ for 14 years. Table 8 shows that the average daily liquid extraction volume of three sets of schemes is $5400 \mathrm{~m}^{3}$, and the total liquid amount is the same. At the end of the prediction period, the production quotas of the three are similar, but in the early stage, the larger the volume is, the faster the pressure of reservoir drops, and the cumulative 
oil production and matrix cumulative oil discharge at the stage are also higher. Considering the maximum volume of liquid extraction for every well in production practice

Table 8. Comparison of production quota of $5400 \mathrm{~m}^{3}$ daily average liquid in variable speed extraction in 20 years

\begin{tabular}{|c|c|c|c|c|c|c|c|c|}
\hline Case name & $\begin{array}{l}\text { Maximum } \\
\text { daily liquid } \\
\text { extraction } \\
\text { per well } \\
\left(\mathrm{m}^{3}\right)\end{array}$ & $\begin{array}{l}\text { Daily liquid } \\
\qquad\left(\mathrm{m}^{3}\right)\end{array}$ & $\begin{array}{l}\text { Daily oil } \\
(\mathrm{t})\end{array}$ & $\begin{array}{c}\text { Composite } \\
\text { water } \\
\text { cut } \\
(\%)\end{array}$ & $\begin{array}{l}\text { Formation } \\
\text { pressure } \\
(\mathrm{MPa})\end{array}$ & $\begin{array}{c}\text { Total pressure } \\
\text { drop } \\
(\mathrm{MPa})\end{array}$ & $\begin{array}{c}\text { Degree of } \\
\text { reserve } \\
\text { recovery } \\
(\%)\end{array}$ & $\begin{array}{c}\text { Cumulative } \\
\text { increment } \\
\text { oil } \\
\left(10^{4} t\right)\end{array}$ \\
\hline Case 9 & 700 & 7255.97 & 23.93 & 99.67 & 23.54 & 5.29 & 33.35 & 29.22 \\
\hline Case 14 & 900 & 6389.00 & 22.20 & 99.65 & 23.60 & 5.23 & 33.36 & 29.35 \\
\hline Case 15 & 1200 & 5786.00 & 20.90 & 99.64 & 23.67 & 5.16 & 33.37 & 29.45 \\
\hline
\end{tabular}

\section{Conclusions}

(1) The depressurization development of reservoirs can promote the oil discharge of small or medium-sized fracture and matrix by reducing the pressure of reservoir. Different depressurization methods are adopted for the reservoirs with different energy, for the water-oil volume ratio close to Y's, this type of reservoir is recommended to use liquid extraction depressurization method.

(2) No matter it is uniform speed liquid extraction, variable speed liquid extraction or cyclic liquid extraction in the technical policy research of extracting liquid depressurization, it is always the change of liquid amount, so the amount of liquid is the most important factor to affect the liquid extraction depressurization. The larger the amount of liquid extraction is, the greater the pressure of the reservoir drops, and the elastic oil discharge function of the matrix system is better.

(3) The amount of liquid extraction is not as large as possible, it is necessary to consider the variation method in combination with the reservoir. However, it must take the steady production of reservoir and the achievable production conditions of oil well as prerequisite for maximizing depressurization. When the pressure drops to a certain extent, it is necessary to combine with economic benefits and then maintain a stable pressure drop to stabilize production.

(4) For reservoirs with high water cut and large wateroil volume ratio, it is not recommended to use cyclic liquid extraction method including the recovery of original liquid volume or water injection. Because extracting large liquid volume in the early stage, after recovering original liquid volume or water injection, the bottom water or injection water intruding fast will result in a small pressure drop in the reservoir during the stage, and the effect of depressurization is not ideal.

\section{References}

1. S.C. Zhang, Y. Huang, (1997) A new understanding of the remaining oil distribution in Renqiu buried hill. Oil and Gas Recovery Technology, 4(1): 4447.

2. P. Tian, A.Y. Xu, X. Zhang, et al, (1999) Evaluation of unstable waterflood development in the later development stage of Renqiu oilfield. Acta Petrolei does not exceed $1000 \mathrm{~m}^{3}$, therefore, it is preferred choosing case 14 that extracting liquid $8100 \mathrm{~m}^{3}$ for 8 years

then $3600 \mathrm{~m}^{3}$ for 12 years.

Sinica, 20(1): 38-42.

3. X.C. Zhang, J.G. Yuan, J.J. Yu, (1998) Depressurization recovery test of Wumishan oil reservoir. Petroleum Exploration and Development, 25(3):80-82.

4. Q. Mao, J.G. Yuan, J.J. Yu, et al, (2001) The research of simulation of water injection re-applied of Wumishan reservoir (Renqiu). Oil Drilling \& Production technology, 23(2):50-53.

5. R.D. Liu, J.G. Yuan, Q.M. Ke, et al, (1994) The basic method and effect of controlling water and oil with high water cut in later stage of Wumishan reservoir in Renqiu. Oil and Gas Recovery Technology, 1(1):2935 .

6. E.J. Hao, A.Y. Xu, H.Y. Lu, (1998) Numerical simulation study of development adjustment for Wumishan reservoir in Renqiu oil field by pressure drop. Petroleum Exploration and Development, 25(6):47-50.

7. Y.G. Geng, B.Z. Zhang, D. Yang, (2000) Simulation technologies and applying effects in Renqiu buried hill reservoir. Oil Drilling \& Production technology, 22(1):45-50.

8. Z.M. Sun, (2006) Study on production mechanism of stopping injection and pressure relief and utility evaluation in reservoir Shugu1. Fault Block Oil and Gas Field, 13(6):50-52.

9. C.S. Zhao, J.R. Lv, L.J. Gao, (2008) Numerical simulation of depressurization production in Putaohua Oilfield. Fault Block Oil and Gas Field, 15(3):84-86.

10. C.S. Zhao, J.R. Lv, Z. Fu, (2008) Numerical simulation and in situ experiment of depressurization development of Pu-bei II block reservoir in Daqing Oilfield. Fault Block Oil and Gas Field, 32(2): 41-43.

11. S.L. Yang, M.X. Li, H. Chen, et al, (2011) Study of the production degree and contribution ratio of matrix in fractured reservoir during water flooding. Oil Drilling \& Production technology, 33(2):69-72.

12. S.L. Yang, M.X. Li, L.J. Wang, et al, (2011) Producing degree and law of matrix in dual-porosity reservoir. Journal of China University of Petroleum, 35(1):98-101.

13. H. Zheng, Y.C. Su, Y.C. Zhang, et al, (2014) The numerical simulation study on percolation 
characteristics and displacement mechanism of fractured reservoir. Petroleum Geology and Recovery Efficiency, 21(4):79-83.

14. Z.N. Zhang, Z.Q. Meng, Z.Q. Zhu, et al, (2017) The research on the oil displacement efficiency in matrix of fractured buried hill reservoirs in JZS oilfield. Special Oil \& Gas Reservoirs, 24(4):101-105.

15. J. Wang, H.Q. Liu, J. Xia, et al, (2017) Mechanism simulation of oil displacement by imbibition in fractured reservoirs. Petroleum Exploration and Development, 44(5):761-770.

16. J.C. Zhang, J.H. Zhang, Y.H. Yang, et al, (2004) Mechanism of depressurization development of fractured reservoirs for enhancing oil production and in situ experiment. Acta Petrolei Sinica, 25(1): 52-56.

17. Y.Z. Huang, G.H. Shang, Y.M. Chen, et al, (1995) Study on the mechanism of cyclic water flooding with MRI. Acta Petrolei Sinica, 16(4): 62-67.

18. G.G. Fan, (1994) High water cut period development characteristics and discussion on technical boundaries of in Wenliu Oilfield. Fault Block Oil and Gas Field, 1(4): $42-50$.

19. Q.T. Yu, S.F. Zhang, (1993) The research on reservoir numerical simulation of cyclic water flooding. Petroleum Exploration and Development, 20(6):4653.

20. J.C. Zhang, S.Z. Bai, Y.J. Zhang, et al, (2003) Cyclic water flooding experiments and research on mechanism of enhancing oil production. Acta Petrolei Sinica, 24(2):76-80. 